\title{
Teologia e a pesquisa sobre espiritualidade e saúde: um estudo piloto entre profissionais da saúde e pastoralistas
}

\author{
Theology and the research on Spirituality and Health: a pilot study among \\ health professionals and chaplains
}

Mary Rute Gomes Esperandio*

\begin{abstract}
Resumo
A relação entre religiosidade/espiritualidade e saúde tem sido pesquisada no Brasil principalmente pela Medicina e Enfermagem. São poucos os trabalhos que tratam do tema sob a ótica do comportamento e das crenças dos profissionais da saúde e pastoralistas. Este estudo teve por objetivo verificar o modo como a dimensão da religiosidade/espiritualidade é compreendida e integrada (ou não) na prática dos profissionais da área da saúde e pastoralistas em um hospital de Curitiba-PR. O método utilizado foi de natureza quantitativa, de tipo survey, de corte transversal, classificado como descritivo. $O$ instrumento de pesquisa foi composto por um questionário com 35 questões fechadas e 1 semiaberta. Foram sujeitos da pesquisa 100 profissionais da saúde: enfermeiros, técnicos e auxiliares de enfermagem, psicólogos, assistentes sociais, fisioterapeuta, fonoaudiólogos, farmacêuticos, nutricionistas clínicos e pastoralistas. Os resultados apontam que a maioria destes profissionais acredita que a religiosidade/espiritualidade afeta os resultados em saúde e julgam importante ter conhecimento dessa relação. Contudo, são poucos os que reportam integrar a espiritualidade em sua prática de cuidado, por falta de (in)formação sobre essas questões. Conclui-se que a teologia pode contribuir na reflexão teórica sobre espiritualidade e saúde, e na colaboração com outras ciências na formação destes profissionais acerca do tema.
\end{abstract}

Palavras-chave: espiritualidade; saúde; coping religioso-espiritual; profissionais da saúde; pastoralistas.

\begin{abstract}
In Brazil the relationship between religiosity/spirituality and health has been mainly studied by medicine and nursing. There are few studies on the behavior and beliefs of health professionals and chaplains. This study aims to find out how the dimension of religiosity/spirituality is understood and integrated (or not) by health professionals and chaplains in health care in a hospital in Curitiba-PR. The research method is a quantitative survey, cross-sectional and descriptive. The applied instrument consists of a questionnaire with 35 closed questions and 1 semi-structured question. Participants are $n=100$ health professionals: nurses, technicians and nursing assistants, psychologists, social workers, physiotherapists, phonoaudiologists, pharmacists, clinical nutritionists and chaplains. The results indicate that most of these professionals believe that religiosity/spirituality affects health outcomes and they believe it is important to be aware of this relationship. However, only few of them report that they integrate spirituality into their care practice as they lack (in) formation on these issues. We conclude that theology can contribute to a theoretical reflection on spirituality and health, and also to the training of these professionals about the subject, in collaboration with other disciplines.
\end{abstract}

Keywords: spirituality; health; spiritual religious coping; health professionals; chaplains.

\footnotetext{
Artigo recebido em 09 de julho de 2014 e aprovado em 25 de setembro de 2014 .

* Doutora em Teologia (EST,2006), professora adjunta do Programa de Pós-graduação em Teologia da Pontifícia Universidade Católica do Paraná (PUCPR). País de origem: Brasil. E-mail: mresperandio@gmail.com
}

Horizonte, Belo Horizonte, v. 12, n. 35, p. 805-832, jul./set. 2014 - ISSN 2175-5841 


\section{Introdução}

Nas últimas décadas do século 20, e de forma mais acentuada neste início de século, os reconhecidos esforços voltados à promoção do "cuidado integral” ou da “integralidade em saúde"1 evidenciam o quanto alguns aspectos fundamentais da prática do cuidado em saúde têm sido dissociados. A espiritualidade, por exemplo, é uma variável que apenas recentemente vem sendo considerada nos indicadores de saúde. A dissociação desta dimensão da existência humana na prática do cuidado integral parece estar vinculada, tanto ao modo como se vêm construindo e se configurando, ao longo da história, a própria noção de cuidado no contexto da saúde, quanto ao modo como se entende o que vem a ser espiritualidade.

Assim, o presente estudo quer entrar nos debates sobre a relação entre saúde e espiritualidade a partir de um lugar pouco comum às pesquisas sobre esse tema, qual seja, o da perspectiva teológica.

A reflexão sobre a contribuição da teologia aos estudos sobre espiritualidade e saúde terá como base uma pesquisa empírica realizada em um dos hospitais da cidade de Curitiba que atende, prioritariamente, pacientes provenientes do Sistema Único de Saúde. Inicialmente são explicitados os termos espiritualidade e religiosidade. Logo após, de forma não exaustiva, são apresentados alguns dos principais estudos sobre espiritualidade e saúde relacionando tais achados à relevância do tema no âmbito da teologia. Em seguida, discute-se a pesquisa realizada, e são apontadas algumas possibilidades de contribuição da teologia aos estudos voltados à integração da espiritualidade na prática do cuidado em saúde.

\footnotetext{
${ }^{1}$ No verbete "Integralidade em saúde" do Dicionário da Educação Profissional em Saúde, Pinheiro (2009) aponta o termo "integralidade" como um dos princípios doutrinários da política do Estado brasileiro para a saúde, sendo a saúde tomada como direito e como serviço prestado pelo Sistema Único de Saúde (SUS).
} 


\section{Religiosidade, espiritualidade e a pesquisa em saúde}

Embora abarquem sentidos distintos, os termos religiosidade e espiritualidade podem se sobrepor. A noção de espiritualidade, em geral, está referida à dimensão humana onde o sujeito assume algum tipo de crença, quer seja em Deus, em um poder/ser superior, em uma energia cósmica, ou algo transcendente (ainda que sem nome). Por vezes, espiritualidade também se refere à prática de determinadas atividades religiosas, ou exercícios espirituais específicos. Em razão disto, Koenig (2012a, p. 18), um dos mais importantes pesquisadores nessa área, sugere que no trato com o paciente, é mais adequada a utilização do termo "espiritualidade" do que o termo religiosidade, sobretudo, porque além de ser mais amplo e permitir uma interpretação de sentido pela própria pessoa, as crenças religiosas são comuns em pacientes em tratamento médico, e mesmo aqueles que declaram não possuir uma religião consideram-se "espiritualizados", ou que "têm uma espiritualidade". Porém, dada a necessidade de maior precisão nas pesquisas, e porque, em geral, a ideia de espiritualidade pode se confundir com bem-estar psicológico, Koenig defende que a pesquisa busque medir elementos característicos da religiosidade (KOENIG, 2012a, p. 17-19).

Esta diferenciação entre espiritualidade e religiosidade parece estar se constituindo, nas últimas décadas, como senso comum na população em vários contextos culturais, não se restringindo apenas aos Estados Unidos. No Brasil, o último censo realizado pelo Instituto Brasileiro de Geografia e Estatística apresenta, inclusive, uma nova categoria, a dos "evangélicos sem religião", o que corrobora com a ideia de uma "espiritualidade" não ligada a nenhuma forma religiosa específica ou instituída.

A dificuldade de precisão desses dois termos aparece nos estudos sobre o tema. Em uma revisão de literatura sobre adicção, realizada por Cristopher C. H. Cook (apud FORCEHIMES; TONIGAN, 2009, p. 115), o autor examinou 265 publicações para identificar a definição de espiritualidade usada pelos seus autores. 
Apenas 12\% dos artigos definiu o termo espiritualidade claramente, $32 \%$ ofereceu uma descrição do conceito; 12\% definiu um conceito relacionado (como, “a pessoa espiritualmente saudável”) e 44\% dos artigos deixou indefinido o termo espiritualidade. Destrinchando o conteúdo conceitual para ver seus elementos constitutivos, Cook classificou o conteúdo das várias definições em treze componentes conceituais e chegou a quatro elementos mais frequentemente mencionados na definição de espiritualidade. Segundo ele, quatro elementos são centrais na definição de espiritualidade: 1. transcendência, 2. relacionalidade, 3. centro/força/alma, e 4. sentido/propósito .

Assim, para o propósito deste estudo, o termo espiritualidade está sendo usado para se referir à dimensão do ser humano que envolve a busca de sentido e propósito na vida, busca de auto integração e de auto realização; busca de relações humanas satisfatórias e de senso de conexão consigo e com outros, com o universo e com a transcendência (que pode ser um Ser Superior ou força na qual a pessoa acredita). Trata-se, portanto, daquela dimensão humana que se preocupa com as questões mais profundas da existencialidade e da realidade última. No contexto hospitalar, a espiritualidade estará intimamente relacionada ao processo de produção de sentido e propósito do sofrimento que comumente acompanha a doença.

Religiosidade, por sua vez, está sendo tomada como expressão do envolvimento do indivíduo com práticas religiosas que podem ser identificadas com religiões institucionalizadas, podendo ser, portanto, um aspecto da espiritualidade do sujeito. Em geral, o sujeito religioso assume certas crenças, práticas e valores ético-morais ligados a uma religião instituída. Religião, por conseguinte, diz respeito a um fenômeno social definido por limites particulares, expressos num corpo de doutrinas assumidas pela comunidade de fé que partilha das mesmas crenças.

Em relação aos estudos sobre espiritualidade e saúde, uma busca realizada em 2009 pelo professor Moreira-Almeida nos Indexadores PubMed e PsycInfo com 
os termos de busca "religio" e "spiritu", o autor afirma ter encontrado 42.734 artigos no PubMed e 63.116 no PsycInfo, sendo que deste total, quase metade foi publicada nesta última década, sendo 18.478 indexados pelo PubMed e 27.100 artigos no PsycInfo (MOREIRA-ALMEIDA, 2010, p. 41). Embora o Brasil seja considerado um país muito religioso, tais investigações são ainda escassas e pontuais. Essa realidade começa a mudar aos poucos, sobretudo em razão dos resultados apontados:

a ampla maioria dos estudos de boa qualidade encontrou que maiores níveis de envolvimento religioso estão associados positivamente a indicadores de bem estar psicológico (satisfação com a vida, felicidade, afeto positivo e moral mais elevado) e a menos depressão, pensamentos e comportamentos suicidas, uso/abuso de álcool/drogas. Habitualmente, o impacto positivo do envolvimento religioso na saúde mental é mais intenso entre pessoas sob estresse (idosos, e aqueles com deficiências e doenças clínicas) (MOREIRA-ALMEIDA et al., 2006, p. 242).

Nos Estados Unidos, o volume de estudos sobre espiritualidade e saúde cresceu de tal modo que, em 2001, os pesquisadores, Koenig, McCullough \& Larson, publicaram o "Handbook of Religion and Health" (Manual de Religião e Saúde), onde examinaram 1.200 estudos quantitativos, considerados de qualidade, sobre esse tema, realizados no período entre 1872 - 2000. Em 2012, uma segunda edição foi publicada cobrindo o período entre 2000-2010. Em apenas 10 anos houve um acréscimo de 2.100 estudos quantitativos (KOENIG; KING; CARSON, 2012). Pesquisas qualitativas não foram incluídas nessas duas edições. Tais estudos abrangem a relação entre espiritualidade e saúde física e mental sob os mais diversos enfoques, sobretudo na área da Psicologia. Alguns temas têm sido tão amplamente pesquisados que já se constituem como um campo de pesquisa específico, tais como o coping (enfrentamento) religioso espiritual (PARGAMENT, 1997).

Em um artigo onde Koenig discute as implicações dos achados científicos para a prática clínica, o autor lista várias pesquisas com resultados significativos. Um estudo na clínica de doenças pulmonares da Universidade de Pensilvânia 
mostrou que 66\% dos pacientes afirmaram que as suas crenças religiosas influenciariam em suas decisões de tratamento caso eles ficassem gravemente enfermos, e 80\% desta amostra reportou que eles seriam receptivos às perguntas sobre suas crenças religiosas (KOENIG, 2004, p. 1195). Koenig cita ainda, vários outros estudos que apontam que as crenças e práticas religiosas estão associadas com taxas de suicídio mais baixas; menos ansiedade; menos abuso de substâncias; menos depressão e recuperação mais rápida da depressão; maior bem-estar, esperança e otimismo; mais propósito e significado na vida, apoio social superior; maior satisfação e estabilidade conjugal (KOENIG, 2004, p. 1195).

Uma busca não exaustiva das teses e dissertações produzidas no Brasil, assim como dos artigos indexados no Scielo sobre espiritualidade e saúde, apontam que as pesquisas sobre esse tema tem sido desenvolvidas principalmente na área da Saúde, especialmente pela Medicina e Enfermagem. Neste contexto, destacam-se os estudos sobre espiritualidade junto a pacientes com câncer e também sobre coping religioso/espiritual². As investigações sobre coping religioso estão apenas começando no Brasil, mas já se prevê um aumento considerável em um futuro próximo, uma vez que a academia começa a perceber a importância dos estudos sobre como os pacientes se utilizam da religião/espiritualidade para melhor enfrentarem processos de saúde-doença.

Enquanto algumas áreas vêm se despertando para a relevância e necessidade de pesquisas sobre espiritualidade e saúde, no campo da teologia, tais estudos são, até o presente momento, praticamente inexistentes, com a ressalva, entretanto, de que pode ser encontrada alguma reflexão teológica sobre saúde no campo da Bioética, a exemplo dos trabalhos de ÁLVAREZ, 2013; MARTINS; MARTINI, 2012.

\footnotetext{
${ }^{2}$ Coping religioso/espiritual refere-se à utilização de elementos sagrados (religiosos e espirituais) na forma de responder aos eventos estressores, sendo que os métodos de coping religioso podem ser "positivos" ou "negativos". Compõem um padrão de coping positivo, métodos de enfrentamento tais como: posição positiva frente a Deus; coping religioso colaborativo; busca de suporte espiritual, transformação de vida, etc. Já o coping negativo expressa-se por meio de um relacionamento menos seguro com Deus; uma visão de mundo frágil e ameaçadora, e conflitos espirituais na busca por significado (PARGAMENT et al. 1998, p. 712).
} 


\section{Por que pesquisar saúde e espiritualidade no contexto dos estudos em Teologia}

A Teologia não tem um histórico de pesquisa na interface saúde e espiritualidade, e, inclusive, pode parecer estranha tal iniciativa. O estranhamento se dá, talvez, em razão de um certo entendimento do que seja próprio da teologia e do fazer teológico. Neste sentido, faz-se importante explicitar a perspectiva teológica assumida no presente estudo: não se parte de um lugar onde se "fala sobre Deus" (um Deus revelado), mas sim, de um lugar onde se reflete sobre a experiência do ser humano com o que este considera sagrado. Trata-se, portanto, de uma Teologia Prática - uma teologia que parte da prática para refletir sobre as implicações no/para o discurso teológico teórico. Dessa perspectiva, a pesquisa sobre espiritualidade e saúde certamente aponta algumas questões importantes para uma reflexão teológica que se quer contextualizada, atual, construída a partir da realidade concreta do sujeito contemporâneo. No contexto da saúde, em especial, emerge a pergunta sobre o sentido e o propósito do sofrimento.

É notório que no mundo ocidental, as pessoas comumente se voltam para a religião quando enfrentam problemas de saúde. Isto acontece, sobretudo, em razão de que uma das principais características da religião é ajudar as pessoas a lidarem com o sofrimento, com a dor e com o fim da vida. A maioria das pessoas usa métodos de coping religioso em tempos quando a saúde está comprometida, a fim de suportar e superar o estresse advindo de tal situação. Pode-se orar pela cura, por força emocional, ou mesmo a própria comunidade de fé se constitui como fonte de conforto e apoio.

Pargament, criador do conceito de coping religioso/espiritual, tem estudado exaustivamente o papel da religião nos métodos de enfrentamento do estresse. $\mathrm{O}$ autor encontrou relação consistente entre estilos positivos de coping e melhores resultados em saúde mental. Por exemplo, o estilo colaborativo (sujeito e Deus são co-responsáveis e parceiros na solução de problemas), assim como a busca de suporte espiritual (de Deus ou das comunidades de fé), e uma posição positiva 
frente a Deus, são métodos de coping positivo que tem sido relacionados a menos ansiedade (PARGAMENT; KOENIG; PEREZ, 2000) e menos depressão (KOENIG; GEORGE; PETERSON, 1998). Vários estudos têm demonstrado que os métodos de coping religioso são frequentemente usados para lidar com o estresse que emerge na doença crônica (KOENIG; LARSON; LARSON, 2001). Também na doença mental, estudos desenvolvidos nos Estados Unidos e Europa mostram que a religiosidade/ espiritualidade tem um papel significativo no enfrentamento dos sintomas (HEFTI, 2013, p. 249-250). A pesquisa americana de Tepper, aplicada em 406 pacientes em um dos treze serviços de saúde mental do Condado de Los Angeles, replicada na Suiça por Mohr e colaboradores, em 115 pacientes usuários do serviço em saúde mental, mostra que para a maioria dos pacientes (mais de 80\% na pesquisa americana e $71 \%$ da pesquisa na Suiça), a religião proveu esperança, propósito e sentido de vida, sendo que o uso de métodos de coping religioso/espiritual reduziu sintomas psicóticos, aumentou a integração social, e reduziu o risco de suicídio, entre outros efeitos (HEFTI, 2013, p. 249-250). Este é o lado positivo da relação entre religião, espiritualidade e saúde.

Conquanto muitos estudos apontem uma associação positiva entre envolvimento religioso/espiritual e melhor adaptação em situação de doença, quando as atividades e crenças religiosas são levadas à extremo, elas também tem efeitos negativos sobre a saúde mental e física e pode ser causa de vários tipos de sofrimento e de formas de violência. Em nome da religião se justifica, por vezes, a raiva, o ódio e antipatia, a agressão e os preconceitos. Em nome da religião se profere juízos sobre os outros, se excluem pessoas de determinados grupos sociais. A religião pode aprisionar ao invés de libertar, pode ser restritiva da vida ao invés de expandir a vida (KOENIG; LARSON; LARSON, 2001, p. 357). Do mesmo modo, os métodos positivos ou negativos de coping tem um impacto importante nos processos de saúde-doença.

Cummings \& Pargament (2010, p. 38) listaram vários estudos que fracassaram na busca de uma relação positiva entre coping religioso e saúde. Frequência a cultos, oração, experiências espirituais e auto-avaliação sobre a 
importância da religião não apareceram relacionados à depressão em pacientes safenados.

O uso de métodos negativos de coping religioso traz, segundo vários estudos, resultados indesejáveis em saúde. Métodos negativos de coping religioso podem ser exemplificados com crenças envolvendo: uma reavaliação negativa de Deus (como: "Fiquei imaginando se Deus tinha me abandonado; "Culpei Deus pela situação, por ter deixado acontecer”); um posicionamento negativo frente a Deus ("Não tentei lidar com a situação, apenas esperei que Deus levasse minhas preocupações embora"); uma reavaliação negativa do significado ("Convenci-me que forças do mal atuaram para tudo isso acontecer”), e insatisfação com o outroinstitucional ("Senti insatisfação com os representantes religiosos de minha instituição"; "Tive dificuldades para receber conforto de minhas crenças religiosas”). Os métodos negativos de coping levam a uma forma de sofrimento caracterizada como típica de conflitos espirituais ${ }^{3}$. Por exemplo, quando pessoas com doenças graves (ou crônicas) interpretam sua doença como indicação ou prova do abandono de Deus, ou então como punição divina, isso gera dúvidas angustiantes a respeito de sua fé (conflitos espirituais) com efeitos negativos importantes nos processos de saúde-doença (CUMMINGS; PARGAMENT, 2010, p. 42).

Cumming e Pargament (2010, p. 43) apontam os aspectos negativos da relação entre coping religioso/espiritual e saúde, e apresentam um número significativo de estudos que comprovam a relação positiva entre conflitos espirituais e resultados indesejáveis em saúde. Dentre esses estudos, destaca-se o de Hills e colaboradores (2005) junto a pacientes em tratamento paliativo; o de Johnstone \& Yoon (2009) entre pacientes com traumatismo crânio-encefálico,

\footnotetext{
${ }^{3}$ Os estudos de Pargament sobre conflitos espirituais mostram que estes podem ser de três tipos: interpessoal, intrapessoal e divino. Os conflitos espirituais do tipo interpessoal dizem respeito às tensões e embates em torno de questões espirituais relacionadas à família, amigos, clérigos ou comunidades de fé. Os conflitos espirituais do tipo intrapessoal têm como foco tanto as questões internas e dúvidas relacionadas à fé, quanto os conflitos intrapsíquicos envolvendo certos aspectos da subjetividade. Os conflitos espirituais do tipo divino se caracterizam por emoções negativas direcionadas a Deus, tais como raiva, ansiedade medo, e sentimentos de abandono (PARGAMENT, 2013, p. 265).
} 
lesão medular, ou AVC; e o de Sherman e colaboradores (2005) junto a pacientes com câncer. Este último observa que pacientes que reportaram estar vivenciando conflitos espirituais relataram, por conseguinte, maior dor e menos energia (SHERMAN et al., 2005). O estudo de Trevino e colaboradores (2010) mostra que a carga viral e os sintomas de HIV foram positivamente relacionados com o coping religioso negativo. Cumming e Pargament (2010, p. 43) se mostraram impressionados com o estudo longitudinal de dois anos, conduzido por Pargament e colaboradores, que aponta relação positiva entre o uso de coping religioso negativo e a previsão de maior risco de mortalidade entre pessoas idosas com doença crônica (PARGAMENT et al., 2001).

Diante do acima exposto pode-se perceber a relevância da reflexão teológica do ponto de vista teórico e prático. Os sofrimentos religiosos-existenciais que se configuram nos processos de saúde-doença convocam a teologia a oferecer uma reflexão que leve em conta a existência concreta do sujeito, sua relação com aquilo que o transcende, sua busca de sentido e propósito na vida expressos em seus questionamentos acerca dos eventos cotidianos que se apresentam como lugar de produção de sentido no processo existencial. A teologia ocupa, assim, um lugar privilegiado na produção de discursos de verdade sobre a vida (tanto da vida enquanto bios, a vida biológica, quanto no aspecto da vida como zoé, a vida qualificada). As verdades produzidas e veiculadas pela teologia tem poder tanto de afirmar a vida quanto restringi-la. A exemplo disso, pode-se pensar no caso das pessoas que contraem doenças graves em razão de um comportamento que a religião, em geral, classifica como pecaminoso, tais como uso de drogas ou atividades sexuais, podem enfrentar profundos conflitos em sua comunidade de fé e até mesmo sofrer a evitação/exclusão pelos demais. Nesse sentido, tratar teologicamente as questões relacionadas aos conflitos espirituais e às estratégias negativas de coping no campo da saúde pode se constituir numa contribuição significativa da Teologia aos estudos na interface espiritualidade e saúde. Mas, certamente, outras formas de contribuição se farão aparecer a partir das pesquisas sobre esse tema, como ilustra o presente estudo. 


\section{A pesquisa: Crenças, Atitudes, Experiências e Expertise dos Profissionais da Saúde e Pastoralistas}

Em uma recente revisão de literatura em língua portuguesa sobre oração e saúde, a oração foi apontada como um dos métodos de coping mais utilizadas pelos pacientes nos processos de saúde-doença (ESPERANDIO, 2014, p. 54).

Embora o Brasil seja um país considerado profundamente religioso e haja muitos estudos apontando o importante papel que religiosidade/espiritualidade exerce no processo de tratamento das doenças, pouco se tem estudado sobre como os profissionais da saúde lidam com essa questão na prática dos cuidados em saúde. Sabe-se que as crenças religiosas podem funcionar tanto como um recurso no tratamento, facilitando o cuidado, como pode, ao contrário, conflitar e interferir neste processo (HEFTI, 2013, p. 121).

Os estudos de Balboni et al. (2007; 2010) e Williams et al. (2011) mostram que muitos dos pacientes hospitalizados com doenças crônicas apresentam necessidades espirituais. Tais necessidades quando não atendidas têm "consequências significativas em termos de qualidade de vida, satisfação com os cuidados, e demanda, algumas vezes, de serviços fúteis de cuidado em saúde" (apud, 2012b). Entretanto, questões ligadas à religiosidade/ espiritualidade dos pacientes raramente são consideradas durante o curso do tratamento hospitalar pelos profissionais da saúde. No Brasil, no dia-a-dia do contexto hospitalar, as necessidades espirituais dos pacientes têm sido objeto de preocupação de religiosos e/ou leigos que, em geral, buscam fazer esse trabalho como voluntários, não sendo portanto conhecidos - porque não pesquisados - os efeitos de tais ações. As razões possíveis para a "negligência" dessas questões por parte dos profissionais da saúde passam, tanto pelo desconhecimento teórico (ausência de formação) quanto prático (não sabem como fazer essa integração). Também a sobreposição dos conceitos religiosidade e espiritualidade parece ter contribuído na construção dessa "cultura" de negligência. Tomadas como sentido equivalente, se construiu uma prática de que as necessidades espirituais/religiosas devem ser atendidas pelo 
pastoralista, sem levar em conta que o cuidado integral também envolve aspectos ligados à espiritualidade - no sentido como tal dimensão está sendo aqui abordada.

Assim, na pesquisa intitulada "Espiritualidade e Saúde: Crenças, Atitudes, Experiências e Expertise dos Profissionais da Saúde e Pastoralistas” buscou-se verificar o modo como a dimensão da religiosidade/espiritualidade tem sido compreendida e integrada na prática dos profissionais da área da saúde e pastoralistas. Os objetivos foram expressos do seguinte modo: 1. Evidenciar as crenças, atitudes, experiências e expertise (habilidade) dos profissionais da saúde e pastoralistas sobre saúde e espiritualidade; 2. Identificar dificuldades e possibilidades de integração da espiritualidade nos serviços de saúde; 3. Verificar o uso de estratégias de coping religioso-espiritual pelos profissionais da saúde no exercício da prática profissional.

\subsection{Método e Procedimentos}

O método de pesquisa utilizado foi de natureza quantitativa, de tipo survey, de corte transversal (a coleta de dados ocorre em um só momento), e é classificada como descritiva. A pesquisa survey é adequada quando se quer produzir descrições quantitativas de uma população e se faz uso de um instrumento pré-definido (FREITAS et al. 2000, p. 105). Seu propósito é "identificar quais situações, eventos, atitudes ou opiniões estão manifestos em uma população” (FREITAS et al., 2000, p. 106). Freitas e colaboradores observam que este método é apropriado "quando: se deseja responder questões do tipo ‘o quê?', 'por quê?', ‘como?', e ‘quanto?', ou seja, quando o foco de interesse é sobre ‘o que está acontecendo’ ou como e porque isso está acontecendo" (FREITAS et al., 2000, p. 105). Assim, para a coleta de dados, foi elaborado um questionário com 36 questões, sendo 35 perguntas fechadas e 1 pergunta semiaberta. O questionário foi dividido em 5 seções. A seção I reuniu questões com vistas ao levantamento sócio demográfico, tais como idade, gênero, estado civil atual, ocupação profissional, nível de escolaridade e afiliação 
religiosa. A seção II buscou levantar: o conceito de espiritualidade e de religiosidade do respondente; a relação que o profissional vê entre os dois conceitos; e uma auto avaliação da própria religiosidade/espiritualidade. A seção III levantou dados sobre a relação entre religiosidade/espiritualidade e (resultados em) saúde; a seção IV enfocou questões sobre coping (enfrentamento) religiosoespiritual e, por fim, a seção V investigou o modo como a espiritualidade tem sido tratada na formação e prática dos profissionais da saúde e dos pastoralistas.

A pesquisa atendeu às normas éticas, tendo sido submetida à avaliação pelo Comitê de Ética em Pesquisa da PUC,4 e teve início no ano de 2012, após sua aprovação pelo referido comitê. O Hospital Universitário Cajuru, primeiro local para coleta de dados, é vinculado à Aliança Saúde do Grupo Marista, e conta, atualmente, com cerca de 950 colaboradores profissionais da saúde que representam as seguintes ocupações: psicólogo/a, enfermeiro/a, técnico em enfermagem, auxiliar de enfermagem, serviço social, fisioterapeuta, fonoaudiólogo/a, farmacêutico/a, nutricionistas clínicos e pastoralistas que se ocupam do serviço de capelania hospitalar5. Planeja-se repetir a pesquisa nos vários hospitais de Curitiba ${ }^{6}$.

Foram adotados como critérios de inclusão na pesquisa, a participação voluntária, ser maior de 18 anos, ser capaz de ler e compreender as questões, e ainda, estar filiado à instituição por pelo menos um ano. Este último critério buscou garantir por parte do/a respondente, um conhecimento adequado do local de trabalho, com tempo suficiente de prática profissional para analisar sua própria atuação.

\footnotetext{
${ }^{4}$ Parecer Consubstanciado no. 48582, de 27.06.2012. Os sujeitos da pesquisa assinaram o Termo de Consentimento Livre e Esclarecido, guardados em poder da pesquisadora. Os dados foram coletados por um aluno participante do Programa Institucional de Bolsas de Iniciação Científica (PIBIC) acompanhado de perto pela pesquisadora. Registro o agradecimento ao aluno de Graduação em Teologia, Geilson A. S. Machado, pesquisador do Programa Institucional de Bolsas de Iniciação Científica.

${ }^{5}$ Por solicitação do próprio local, os médicos não participaram desta coleta de dados. Contudo, um levantamento à parte, com amostra restrita à população médica, está sendo realizado neste ano de 2014.

${ }^{6}$ Em 2013-2014, foram coletados os dados na Santa Casa de Misericórdia de Curitiba. A pesquisa nesse local está em vias de finalização. Um aluno de Mestrado vem pesquisando o tema no Hospital Evangélico. De forma que em breve estará disponível um mapeamento da cidade de Curitiba sobre se/como os profissionais da saúde e pastoralistas integram as questões da espiritualidade nas práticas de cuidado em saúde.
} 
Compuseram a amostra, 100 profissionais da saúde, representando pouco mais de 10\% do total de colaboradores, categorizados do seguinte modo: 36 técnicos em enfermagem, 25 enfermeiros, 24 auxiliares de enfermagem, 03 psicólogos, 02 assistentes sociais, 01 fisioterapeuta, 02 fonoaudiólogos, 03 farmacêuticos, 02 nutricionistas clínicos e 02 pastoralistas7.

\subsection{Resultados}

A análise dos dados foi processada por meio do SPSS (Statistical Package for the Social Science 21.v), uma ferramenta de informática que analisa estatisticamente cálculos complexos de forma rápida e confiável ${ }^{8}$. Como recurso para a análise dos dados aqui obtidos, procedeu-se a análise fatorial exploratória (composta da análise fatorial; análise da consistência interna e a análise da validade convergente discriminante), o que nos permitiu explorar as correlações entre as variáveis obtidas no processo de formulação do questionário aplicado e verificar a necessidade de refinamento do questionário para novas aplicações.

\subsubsection{Perfil Sócio-demográfico}

A maioria dos respondentes, 67\%, é do gênero feminino, 26\% masculino e $7 \%$ identificados como "outros gêneros”. A pesquisa considerou neste quesito a “identidade de gênero", isto é como o indivíduo se sente e se apresenta frente ao mundo, como homem, mulher ou ainda fora deste padrão. A média de idade dos entrevistados é de 35,2 anos, sendo o mais novo com 21anos e o mais velho com 64 anos. Mais da metade dos respondentes, 56\%, possui escolaridade de nível médio e ou técnico, enquanto 5\% possui nível superior incompleto, 25\% nível superior completo, e 14\% da amostra total possui pós graduação (Mestrado/Doutorado). O tempo de atuação profissional na área de saúde varia entre 01 e 41 anos, sendo que

\footnotetext{
${ }^{7}$ O número de sujeitos pesquisados seguiu a regra estatística que considera $10 \%$ como uma amostra estatisticamente confiável. Contudo, nas categorias profissionais onde o número de sujeitos colaboradores é baixo (psicólogo, assistente social, fisioterapeuta, fonoaudiólogo, farmacêutico, nutricionista e pastoralista), a coleta de dados foi realizada em $100 \%$ dos sujeitos representantes dessas profissões no local pesquisado.

${ }^{8}$ A estatística descritiva da pesquisa está em anexo, ao final deste estudo.
} 
46.9\% dos respondentes atuam de 01 a 05 anos na área, 20.1\%, 6 a 10 anos de atuação, e 31,7\% estão há mais de 10 anos na área. Destes, 74\% atuam no período diurno enquanto $15 \%$ atuam no período noturno e $11 \%$ desenvolvem suas atividades em ambos os turnos. Quanto a média de filhos 35,35\% dos respondentes não possuem filhos, enquanto 41,5\% possuem de um a dois filhos e outros $23 \%$ possuem mais de três filhos. Indagados sobre suas práticas e afiliação religiosa (Tabela 01), uma pequena porcentagem, 5\%, declarou-se ateia, 9\% sem religião (embora admitam crer em Deus) e 3\% evangélico sem filiação religiosa. A maioria, cerca de 58\% se declara católica (praticante ou não).

Tabela 1 - Afiliação Religiosa

\begin{tabular}{|c|c|}
\hline AFILIAÇÃO RELIGIOSA & $\%$ \\
\hline Ateu não acredita Deus & 5,00 \\
\hline Sem religião, acredita em deus & 9,00 \\
\hline Católico praticante & 30,00 \\
\hline Católico não Praticante & 28,00 \\
\hline Evangélico não filiado & 3,00 \\
\hline Protestantes (Batista, Menonitas e Luteranos) & 7,00 \\
\hline Adventista & 2,00 \\
\hline Espírita & 5,00 \\
\hline Afro-brasileiras & 1,00 \\
\hline Assembleia de Deus & 1,00 \\
\hline Neopentecostais & 8,00 \\
\hline Quadrangular, Igreja Deus é amor, & 1,00 \\
\hline Outros (Budista) & 100,0 \\
\hline Tniversal do Reino de Deus, Bola de Neve) & \\
\hline Toral & \\
\hline
\end{tabular}

Fonte: Dados da pesquisa

Os dados a respeito da religião aproximam-se das estatísticas oficiais, apontadas pelo Instituto Brasileiro de Geografia e Estatística. 


\subsubsection{A percepção da noção de espiritualidade/religiosidade e da função da religião na vida privada e na prática profissional}

Perguntados se consideram-se "religiosos" ou "espiritualizados", $28 \%$ deles consideram-se pessoas religiosas, $27 \%$ se identificam como "religiosos e espiritualizados", 14\% se apresentam como "espiritualizados mas não religiosas", e $21 \%$ se definem como "mais espiritualizados que religiosos". Uma pequena parcela, 9\%, se identificam como não sendo "nem religiosas e nem espiritualizadas".

Quando questionados sobre a diferença entre espiritualidade e religiosidade e qual o entendimento acerca de cada um desses conceitos, $31 \%$ afirmam que espiritualidade é um conceito mais amplo do que religiosidade e inclui este último, $31 \%$ entendem que os conceitos de religiosidade e espiritualidade diferem entre si e não se sobrepõem, $27 \%$ afirmam que estes conceitos diferem entre si mas podem ser sobrepostos, $9 \%$ acreditam que o conceito de religiosidade é mais amplo que o de espiritualidade e inclui este último, e apenas $2 \%$ da amostra entendem religiosidade e espiritualidade como sinônimos. Ou seja, a maioria dos sujeitos pesquisados, 58\%, compreendem espiritualidade e religiosidade como conceitos distintos, embora possam se referir à mesma coisa.

Da amostra pesquisada, 39\% frequentam algum templo e atividades religiosas pelo menos uma ou mais vezes na semana, 33\% algumas vezes por ano, e apenas $11 \%$ frequenta atividades religiosas uma vez ao ano ou nunca. Já em relação às práticas religiosas privadas, $51 \%$ reportam alguma prática espiritual/religiosa diária. $12 \%$ dos respondentes afirmam participar de atividade religiosa uma vez por semana, $12 \%$ poucas vezes ao mês, e apenas $11 \%$ afirmam raramente ou nunca participar de nenhuma atividade religiosa.

Ao relacionar espiritualidade/religiosidade e sua influência na prática do exercício profissional, parte dos respondentes, 68\%, afirmam que espiritualidade/ religiosidade influi no modo como eles encaram seu trabalho, 18\% não tem certeza desta relação, e 14\% afirmam que sua espiritualidade/religiosidade nada tem a ver com sua prática profissional. 


\subsubsection{A percepção dos profissionais sobre a relação entre religiosidade/ espiritualidade e saúde}

Na seção em que se investigou as estratégias de coping religioso (o quanto a religião é utilizada para lidar com situações estressantes) empregada pelos próprios profissionais da saúde, $83 \%$ deles fazem uso de estratégias religiosas/espirituais para dar conta dos próprios sofrimentos, $3 \%$ não têm certeza se busca na dimensão espiritual recursos para dar conta do sofrimento, 9\% usam de vez em quando e 4\% nunca se utilizam de tais meios para lidar com o sofrimento.

Ao verificar se na opinião dos profissionais da saúde, pessoas com problemas de saúde se voltam mais facilmente para questões religiosas, a pesquisa evidenciou que $80 \%$ dos respondentes concordam com esta afirmação enquanto $13 \%$ discordam totalmente.

No que diz respeito a relação negativa da espiritualidade/religiosidade no tratamento de saúde, $80 \%$ dos profissionais acreditam que a religião não interfere negativamente, 9\% são neutros e 11\% acreditam que há uma interferência negativa da religião sobre a saúde.

Sobre a relação entre religião e saúde mental 60\% dos profissionais não acreditam que a religião cause problemas de saúde e sobretudo de saúde mental, 15\% são neutros, e 25\% acreditam que questões religiosas podem levar as pessoas a terem problemas de saúde e até mesmo de saúde mental. Em contrapartida, 76\% dos profissionais concordam que a religiosidade coopera na promoção da saúde humana, já outros $21 \%$ são neutros e 3\% afirmam que a religiosidade em nada contribui para a promoção da saúde.

Uma percentagem significativa de profissionais, 82\%, acreditam que é importante compreender a relação entre saúde e espiritualidade, 13\% são neutros, e 5\% não vêm isso como importante. 
Quando perguntados sobre a importância de reconhecer as necessidades espirituais dos pacientes, 68\% dos profissionais acreditam que isso é importante; 21\% são neutros, e 11\% discordam que haja alguma importância o reconhecimento das necessidades espirituais dos pacientes.

\subsubsection{Integração da Religiosidade/espiritualidade e saúde, e a formação dos profissionais.}

$\mathrm{Na}$ última seção, o instrumento buscou investigar o modo como a espiritualidade é tratada na formação e prática dos profissionais da saúde e dos pastoralistas.

Quando indagados se se sentem confortáveis em abordar questões religiosas/espirituais durante o processo de tratamento, 51,1\% dos respondentes disseram que sim, outros 15,3\% afirmaram não estar certos, ao passo que 29,6\% responderam não se sentirem confortáveis em abordar questões religiosas/ espirituais durante o tratamento.

Em contrapartida, ao avaliar a importância de se ter conhecimento de questões relativas a religiosidade/espiritualidade dos pacientes, 65,3\% dos respondentes afirmam que tal conhecimento é importante, 26,5\% não possuem opinião a respeito e $8,2 \%$ discordam que seja importante saber de questões acerca da fé dos pacientes.

Ao serem perguntados se abordam questões espirituais junto aos pacientes, 18.1\% dos profissionais reportaram fazê-lo com frequência, 20,2\% algumas vezes, 21,2\% poucas vezes, 21,2\% quase nunca, e 19,2\% dos profissionais responderam que nunca o fazem. Indagados a respeito da percepção do desejo dos pacientes de trazerem questões religiosas ao tratamento, 53\% dos profissionais reportam que os pacientes gostariam de trazer tais questões para o tratamento, 39\% não emitiram opinião sobre isto e outros $7 \%$ discordam que este seja um desejo dos pacientes. 
Sobre a formação do profissional da área de saúde, 68\% julgam tal formação importante, $23 \%$ não concordam nem discordam e $9 \%$ discordam da necessidade desta formação.

Ao verificar a importância da atuação de um pastoralista ou líder religioso no atendimento às necessidades espirituais dos pacientes junto ao hospital, 77\% dos respondentes concordam com a importância do trabalho do pastoralista (ou capelão hospitalar), 16\% não concordam nem discordam e 7\% não concordam. Já quando perguntados se encaminhariam ou não pacientes a estes pastoralistas e líderes religiosos, 58\% afirmam que sim, outros $8 \%$ encaminhariam se soubessem que este profissional está apto para tal atendimento, 17\% afirmam que talvez encaminhariam, 9\% não sabem se o fariam e 4\% reporta que não encaminharia. Dois por cento afirmam não saber o que faz um capelão hospitalar.

Os profissionais foram perguntados a respeito de oportunidades de integração da religiosidade/espiritualidade na prática do cuidado aos pacientes: 18\% reportaram nunca ter tido esta oportunidade, 68\% afirmaram pouca ou algumas vezes, $3 \%$ a realizam de forma frequente, $7 \%$ quase sempre, e apenas $2 \%$ sempre.

Ao serem convidados a relatar a experiência de integração da espiritualidade na prática do cuidado aos pacientes quase metade dos profissionais, 42\%, não responderam a esta questão, outros 12\% afirmaram que tal integração não se aplica a sua área de atuação, 8\% afirmaram não ter tido oportunidade de fazê-lo, e 38\%, deles tentaram descrever suas experiências. Um por cento dos respondentes reportou ter tido uma experiência negativa de integração.

Para o tratamento do material resultante dessa última questão, foi utilizado o método de análise de conteúdo 9 . A análise qualitativa destas respostas apontou 4 categorias:

\footnotetext{
${ }^{9}$ O método de Análise de Conteúdo constitui-se de um conjunto de técnicas utilizadas na análise e interpretação de dados qualitativos. Ver Bardin (2006).
} 
1. Atitude de empatia: $15 \%$ relatam integrar a espiritualidade/ religiosidade através de uma atitude de acolhimento da dor, do tratar bem o paciente e não fazer diferenciação por motivos religiosos;

2. Despertar a consciência espiritual: $7 \%$ dos profissionais referem despertar a consciência espiritual dos pacientes buscando motivá-los a usar a espiritualidade para vencer a enfermidade e o sofrimento;

3. Integração dessas questões com a família e equipe médica: $5 \%$ dos respondentes buscam integrar questões da espiritualidade em conjunto com a família e equipe médica, sobretudo em caso de pacientes terminais. Para estes profissionais, a espiritualidade coopera no enfrentamento da morte e é fonte de conforto para tais pacientes;

4. Integração de forma confessional/catequética: nesta categoria, a experiência descrita aponta a ênfase em conteúdos religiosos-confessionais. Apenas 1\% dos respondentes é da opinião que não se deve integrar a dimensão da religiosidade/espiritualidade na prática dos cuidados em saúde e 5\% expressam o desejo de aprender como fazê-lo.

\subsection{Discussão}

Os sujeitos pesquisados afirmam sentir em sua vida a presença do divino (ou, do sagrado, de um Ser Superior, de Deus, do Espírito Santo, ou algo maior que ele mesmo). A religiosidade/espiritualidade é uma dimensão viva na maioria da amostra estudada, 91\% dos respondentes.

Os profissionais fazem distinção entre os conceitos de espiritualidade e religiosidade, sendo a noção de espiritualidade mais ampla do que de religiosidade, havendo necessidade de levantar com mais precisão como tais profissionais percebem tal distinção. Para eles, a religiosidade influi no modo como encaram seu trabalho (68\%), contudo, apenas $27 \%$ deles confirmam que estes conceitos (religiosidade/espiritualidade), influenciam diretamente sua prática cotidiana. 
Outra relação interessante vincula-se diretamente à prática do coping religioso. Os profissionais de saúde se utilizam de estratégias religiosas para lidarem com situações estressantes em seu dia-dia: 83\% dos respondentes utilizam a espiritualidade para dar conta dos próprios sofrimentos. Contudo, apenas 51\% se sentem confortáveis para abordar questões religiosas para lidar com o sofrimento dos pacientes, e apenas $18 \%$ perguntam com frequência a seus pacientes sobre questões vinculadas a espiritualidade. Para a maioria, 76\%, a religiosidade/ espiritualidade coopera na promoção da saúde humana e julgam importante ter conhecimento sobre a relação entre espiritualidade e saúde.

Interessante notar que a despeito de $82 \%$ dos respondentes assinalarem a importância da integração entre espiritualidade e saúde, quando convidados a relatarem alguma experiência pessoal de integração, apenas 31\% reportaram tê-lo feito de alguma forma. Ou seja, reconhece-se a importância de integração da espiritualidade nos serviços em saúde, mas o fato de não saber fazê-lo pode ser uma das principais razões porque não o fazem.

Os profissionais que integram espiritualidade aos cuidados em saúde através de atitudes de empatia relatam sua experiência do seguinte modo: "Cuido do paciente de maneira como gostaria de ser tratado" (Respondente $\mathrm{n}^{0}{ }_{11}$ ) e "Acho que apoiar meu paciente já é espiritualidade" (Respondente $\mathrm{n}^{0} 35$ ).

Despertar a consciência espiritual é compreendida como uma das maneiras de integrar a espiritualidade na prática do cuidado em saúde: "Busco despertar a consciência nos pacientes da necessidade de uma vivência espiritual, procuro conceder aos mesmos uma motivação para vencerem a enfermidade $e$ o sofrimento" (Respondente $\mathrm{n}^{\circ} 42$ ).

Há, por outro lado, a percepção de que tal integração não se restringe às necessidades espirituais apenas do paciente, mas precisa ser ampliada também em conjunto com a família e equipe médica: "Frequentemente quando um entequerido está na UTI em estado grave de saúde, os familiares e equipe buscam 
o aspecto espiritual para confortar e compreender o processo do morrer e a morte" $\left(R n^{o} 21\right)$.

A integração entre saúde e religiosidade de forma catequética/ confessional é realizada por um número muito restrito de profissionais, e evidencia uma forma específica, talvez particular, de compreender o papel da religiosidade nos cuidados em saúde: “Quando alguém está enfermo, fica vulnerável, então aceita Jesus, e essa é a nossa missão, falar de Deus e de seus ensinamentos, levar a palavra até eles, e muitos ficam felizes e até agradecem" ( $\left.\mathrm{R} \mathrm{n}^{\circ} 85\right)$.

O baixo percentual (31\%) de integração efetiva da espiritualidade/ religiosidade na prática do cuidado em saúde parece estar relacionado à falta de formação específica ou precária sobre a questão, ou ainda, pela não oportunidade de refletir sobre o assunto por parte dos profissionais.

Harold Koenig (2004, p. 1194) já observara tais dificuldades em suas pesquisas e afirmou que não só a maioria dos médicos não têm a formação necessária, mas eles se preocupam também com o gasto de mais tempo com os pacientes, além da preocupação adicional de ultrapassar limites éticos. Koenig pontua, entretanto, que embora estas preocupações sejam válidas, esta questão pode ser abordada de uma forma sensível. O autor sugere que os profissionais tomem a história espiritual do paciente, apoiem suas crenças, e organizem o atendimento das necessidades espirituais de forma integrada ao tratamento (KOENIG, 2004, p. 1194). 


\section{Conclusão}

Além de evidenciar as crenças, atitudes, experiências e expertise (habilidade) dos profissionais da saúde e pastoralistas sobre a relação entre saúde e espiritualidade, a presente pesquisa oportunizou aos profissionais de saúde do hospital, uma reflexão pessoal acerca da integração da religiosidade/ espiritualidade nos serviços de saúde. Embora muitos destes profissionais cultivem alguma forma de culto religioso, julguem importante ter conhecimento acerca de questões espirituais, e acreditam que a religiosidade/espiritualidade afeta os resultados em saúde, poucos integram de forma efetiva a dimensão espiritual em sua prática profissional.

Ao refletirem sobre esse importante tema, os profissionais se depararam com questões da própria espiritualidade, de seu cultivo (ou não), e a relação da mesma com sua prática diária de cuidados em saúde. O tempo investido na pesquisa os levou a pensar sobre um tema normalmente desconsiderado no labor profissional. A pesquisa evidenciou ainda, a falta de informação e formação dos profissionais da saúde a respeito das questões relativas à espiritualidade, assim como despertou também o desejo de receberem mais (in)formação sobre o tema.

Os resultados sugerem a necessidade de refinamento do próprio questionário nas pesquisas futuras ${ }^{10}$, de modo a trazer maior precisão na resposta a algumas questões. Uma diferenciação mais clara das noções de espiritualidade e religiosidade seria uma destas questões. Contudo, fica evidente que uma das contribuições da teologia poderia ser uma reflexão teórica sobre espiritualidade.

A teologia pode contribuir com outras ciências e áreas do conhecimento, sobretudo com os profissionais da saúde, tanto no fomento de uma reflexão consistente sobre esse tema, quanto na oferta de cursos breves de formação destes

\footnotetext{
${ }^{10} \mathrm{O}$ prosseguimento da pesquisa em outros hospitais de Curitiba já conta com o refinamento do questionário utilizado no presente estudo. Caminha-se para a construção/validação de uma "Escala de avaliação das crenças, atitudes, experiência, e expertise dos profissionais da saúde e pastoralistas".
} 
profissionais acerca de questões práticas que envolvem espiritualidade e resultados em saúde. Tais cursos poderiam abordar temas como coping religioso/espiritual, conflitos espirituais, e os riscos e desafios da integração da espiritualidade na prática do cuidado em saúde.

A pesquisa também evidenciou o importante papel que pode ter um pastoralista (capelão hospitalar) na equipe multidisciplinar de um hospital, desde que o mesmo apresente preparo adequado para prover efetivo cuidado e aconselhamento espiritual. Também se espera que a teologia contribua numa melhor formação de capelães hospitalares para atuarem especificamente em tais contextos. Pesquisas que levantem dados sobre espiritualidade e saúde do ponto de vista dos pacientes também se fazem necessárias como complemento do presente estudo.

Cuidado e saúde são linhas que tecem a experiência do humano na contemporaneidade. Focalizar as questões da religiosidade/espiritualidade contemporânea composta nessa trama onde os processos de saúde-doença se configuram é um dos desafios das várias ciências (não de alguma delas em particular) que se interessam pelo estudo do cuidado, da saúde, da qualidade de vida e as possíveis aplicações dos resultados destes estudos na produção de uma vida melhor na sociedade hoje. 


\section{REFERÊNCIAS}

ÁlVAREZ, F. Teologia da Saúde. São Paulo: Paulinas; Centro Universitário São Camilo, 2013.

BALBONI, T. A.; PAULK, M. E.; BALBONI, M. J.; PHELPS, A. C.; LOGGERS, E. T.; WRIGHT, A. A., et al.. Provision of spiritual care to patients with advanced cancer: Associations with medical care and quality of life near death. Journal of Clinical Oncology, Alexandria, VA, v. 28, n. 3, p. 445-452, 2010.

BALBONI, T. A.; VANDERWERKER, L. C.; BLOCK, S. D.; PAULK, M. E.; LATHAN, C. S.; PETEET, J. R., et al.. Religiousness and spiritual support among advanced cancer patients and associations with end-of-life treatment preferences and quality of life. Journal of Clinical Oncology, Alexandria, VA, v. 25, n. 5, p. 555-560, 2007.

BARDIN, L. Análise de conteúdo. Lisboa: Edições 70. 2006 (1977).

CUMMINGS J.P.; PARGAMENT K. I. Medicine for the Spirit: Religious Coping in Individuals with Medical Conditions. Religions, Basel, Switzerland, v. 1, n. 1, p. 28-53, 2010 .

ESPERANDIO, M. R. G. Prayer and Health. A Portuguese Literature Review. Rev. Pistis Prax., Teol. Pastor., Curitiba, v. 6, n. 1, p. 51-66, jan./abr. 2014.

FORCEHIMES, A.; TONIGAN, J. S.. Spirituality and Substance Use Disorders. In.: HUGUELET, Philippe; KOENIG, Harold (ed.). Religion and Spirituality in Psychiatry. New York: Cambridge University Press, 2009. p. 114-127.

FRANCO, T. B.; MAGALHÃES JÚNIOR, H. M. A Integralidade na Assistência à Saúde: a organização das linhas do cuidado. In: MERHY, E. E. et al. (Org.). 3. ed. O Trabalho em Saúde: olhando e experienciando o SUS no cotidiano. São Paulo: HUCITEC, 2006. p. 125133 .

FREITAS, H.; OLIVEIRA, M.; SACCOL, A. Z.; MOSCAROLA, J. O Método de Pesquisa Survey. Revista de Administração São Paulo. São Paulo, v. 35, n. 3, jul/set, p. 105112, 2000.

HEFTI, R. Integrating Spirituality into Therapy. In: HUGUELET, P.; KOENIG, H. (ed.). Religion and Spirituality in Psychiatry. New York: Cambridge University Press, 2009. p. 244-267.

HEFTI, R. The Extended Biopsychosocial Model: a whole-person-approach to psychosomatic medicine and psychiatry. Psyche \& Geloof, Roodeschool, Netherland, v. 24, n. 2, p. 119-129, 2013.

HILLS, J.; PAICE, J.A.; CAMERON, J.R.; SHOTT, S. Spirituality and distress in palliative care consultation. J. Palliat. Med., New Rochelle, NY, v. 8, n. 4, p. 782-788, 2005. 
JOHNSTONE, B.; YOON, D.P. Relationships between the brief multidimensional measure of Religiousness/Spirituality and health outcomes for a heterogeneous rehabilitation population. Rehabil. Psychol., Washington, DC, v. 54, n. 4, p. 422-431, 2009.

KOENIG, H. G. Commentary: Why Do Research On Spirituality And Health, And What Do The Results Mean? J Relig Health. 2012 Jan 19. Disponível em:

<http://www.ncbi.nlm.nih.gov/pubmed/22258735>. Acesso em: 17 fev. 2012b.

KOENIG, H.G. Medicina, Religião e Saúde. O Encontro da Ciência e da Espiritualidade. Porto Alegre: L\&PM, 2012a.

KOENIG, H. G. Religion, Spirituality and Consultation-Liaison Psychiatry. In: HUGUELET, P.; KOENIG, H. (Ed.). Religion and Spirituality in Psychiatry. New York: Cambridge University Press. 2009. p. 190-214.

KOENIG, H. G. Religion, Spirituality and Medicine: Research Findings and Implications for Clinical Practice. Southern Medical Association, Birminghan, AL, Dec; v. 97, n. 12, p. 1194-1200, 2004.

KOENIG, H. G.; GEORGE, L. K.; PETERSON, B.L. Religiosity and Remission of Depression in Medically ill older patienst. Am J Psychiatry, Arlington, VA, v. 155, n. 4, p. 336-542, 1998.

KOENIG, H. G.; KING, D. E.; CARSON, V. B.. Handbook of religion and health (2nd ed.). New York, NY: Oxford University Press, 2012.

KOENIG, H. G.; LARSON, D. B.; LARSON, S. S. 2001. Religion and coping with serious medical illness. Ann Pharmacother, Cincinnati, OH, Mar; v. 35, n.3, p. 352-359. 2001.

KOENIG, H. G.; MCCULLOUGH, M. E.; LARSON, D. B. Handbook of religion and health (1st ed.). New York, NY: Oxford University Press, 2001.

MARTINS, A.A; MARTINI, A. Teologia e Saúde. São Paulo: Paulinas, 2012.

MOREIRA-ALMEIDA, A. O crescente impacto das publicações em espiritualidade e saúde e o papel da Revista de Psiquiatria Clínica. Revista de Psiquiatria Clínica, São Paulo, v. 37, n.2, p. 41-42, 2010.

MOREIRA-ALMEIDA, A.; LOTUFO NETO, F.; KOENIG, H. G. Religiosidade e Saúde Mental: uma revisão. Rev. Bras. Psiquiatr., São Paulo, v. 28, n. 3, p. 242-250, Set. 2006 .

PARGAMENT, K. I.; KOENIG, H. G.; PEREZ, L.M.. The many methods of religious coping: Development and initial validation of the RCOPE. Journal of Clinical Psychology, Malden, MA, v. 56, n. 4, p. 519-543, 2000.

PARGAMENT, K. I.; KOENIG, H. G.; TARAKESHWAR, N.; HAHN, J.. Religious struggle as a predictor of mortality among medically ill elderly patients: A two-year longitudinal study. Archives of Internal Medicine, Chicago, IL, v. 161, n. 15, p. 1881-1885, 2001. 
PARGAMENT, K. I.; SMITH, B. W.; KOENIG, H.G.; PEREZ, L.. Patterns of Positive and Negative Religious Coping with Major Life Stressors. Journal for the Scientific Study of Religion, Malden, MA, v. 37, n. 4, p.710-724, 1998.

PARGAMENT, K. I. Psychology of religion and coping. Theory, Research, Practice. New York: Guilford Press, 1997.

PARGAMENT, K. I. Searching for the Sacred: Toward a Nonreductionistic Theory of Spirituality. In: PARGAMENT, K.; EXLINE, J. J.; JONES, J. W. (ed.). APA Handbook of Psychology, Religion, and Spirituality. v.1. Washington, DC: American Psychological Association, 2013. p. 257-269.

PINHEIRO, R. Integralidade em Saúde. Dicionário da Educação Profissional em Saúde (2a.ed). Rio de Janeiro: Fundação Osvaldo Cruz/Escola Politécnica de Saúde Joaquim Venâncio, 2009. Versão Online. Disponível em:

<http://www.epsjv.fiocruz.br/dicionario/verbetes/intsau.html>. Acesso em: 23 fev. 2014.

SHERMAN, A.C.; SIMONTON, S.; LATIF, U.; SPOHN, R.; TRICOT, G. Religious struggle and religious comfort in response to illness: Health outcomes among stem cell transplant patients. J. Behav. Med., Berlim, v. 28, n. 4, p. 359-367, 2005.

TREVINO, K.M.; PARGAMENT, K.I.; COTTON, S.; LEONARD, A.C.; HAHN, J.; CAPRINIFAIGIN, C.A.; TSEVAT, J. Religious coping and physiological, psychological, social, and spiritual outcomes inpatients with HIV/AIDS: Cross-sectional and longitudinal findings. AIDS Behav., Berlim, v. 14, n. 2, p. 379-389, 2010.

WILLIAMS, J. A.; MELTZER, D.; ARORA, V.; CHUNG, G.; CURLIN, F. A. Attention to inpatients' religious and spiritual concerns: Predictors and association with patient satisfaction. Journal of General Internal Medicine, Berlim, v. 26, n. 11, p. 1265-1271, 2011. 


\section{Anexo}

\section{Tabela 2 - Estatísticas descritivas: Média e desvio padrão}

\begin{tabular}{|c|c|c|c|}
\hline \multicolumn{4}{|l|}{ ESTATISTICAS DESCRITIVAS } \\
\hline Descrição & Média & $\begin{array}{l}\text { Desvio } \\
\text { padrão }\end{array}$ & $\mathrm{N}$ \\
\hline Religião & 5,72 & 5,109 & 100 \\
\hline Conceito Religião x Espiritualidade & 2,85 & 1,559 & 100 \\
\hline Religião/Espiritualidade & 2,72 & 1,364 & 100 \\
\hline Frequência do templo & 3,12 & 1,387 & 100 \\
\hline Frequência da prática & 2,94 & 1,669 & 100 \\
\hline Presença divina & 1,60 & 0,964 & 100 \\
\hline Espiritualidade/Religião influenciam trabalho & 2,23 & 1,238 & 100 \\
\hline Espiritualidade/Religião NÃO influenciam trabalho & 3,52 & 1,527 & 100 \\
\hline Não há relação Espiritualidade/Religião e saúde & 2,25 & 1,298 & 100 \\
\hline Pessoas com Problema de saúde se voltam para relig/espiritualidade & 3,96 & 1,034 & 100 \\
\hline Religião afeta negativamente tratamento & 2,05 & 0,892 & 100 \\
\hline Religião leva à doença mental & 2,40 & 1,341 & 100 \\
\hline Religião/Espiritualidade promove saúde & 4,07 & 0,820 & 100 \\
\hline Profis saúde deve entender saúde x espiritualidade & 4,02 & 0,804 & 100 \\
\hline É importante reconhecer necessidasdes espirituais dos pacientes & 3,71 & 1,066 & 100 \\
\hline Coping religião/espiritualidade me ajuda & 1,92 & 1,085 & 99 \\
\hline Se usa religião para lidar com situação difícil & 3,90 & 1,010 & 98 \\
\hline Integrar questões religiosas/espirituais no tratamento & 3,42 & 1,406 & 98 \\
\hline Importante conhecer religião/espiritualidade do paciente na saúde & 3,62 & 0,711 & 98 \\
\hline Se pergunta sobre religião/espiritualidade aos pacientes & 3,08 & 1,589 & 99 \\
\hline Pacientes gostariam de debater religião/espiritualidade no tratamento & 3,55 & 0,895 & 99 \\
\hline Religião/Espiritualidade na formação & 3,69 & 0,849 & 100 \\
\hline Importância do pastoralista no hospital & 3,97 & 0,915 & 100 \\
\hline Encaminharia a um capelão? & 2,07 & 1,677 & 100 \\
\hline Já integrou Religião/espiritualidade no tratamento dos pacientes & 3,01 & 1,535 & 94 \\
\hline Teve religião/espiritualidade e saúde na sua formação & 1,93 & 0,866 & 95 \\
\hline
\end{tabular}

Fonte: Dados da pesquisa 